266. 深間內久雄，高田美惠子：第一銅塩による沃化物之壏化物の分析的分離について

Hisao Fukamauchi and Mieko Takada : Analytical Separation of Iodide and Chloride by means of their Cuprous Salts.

(Women's Department, Tokyo College of Pharmacy*)

沃素イオンと塩素イオンを分離するには銀塩をアンモニアで処理するのが常法であるが，とれによると分離後

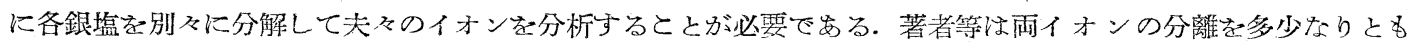
簡易化する为に，第一銅塩の溶解度の差を利用する分離法を検討した。るしてによる分離法が定量的に行われ るならば，両者の共存する場合の各イオンの定性分析が銀塩を経る方法に比較して少ない手数で消さばからでな

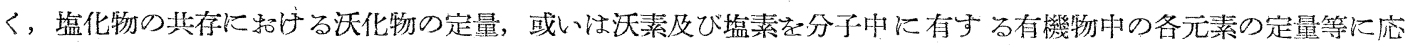
用するととができるすのと考它られる。

塩化第一銅及び沃化第一銅の溶解積はそれぞれ， $L_{\mathrm{CuCl}}=1.02 \cdot 10^{-6}\left(18^{\circ}\right)^{1)}, L_{\mathrm{CuI}}=5.06 \cdot 10^{-12}\left(18^{\circ}\right)^{2)}$ ですつ て，この二つの溶解積值の関係は岕たか子盐化銀と沃化銀との関係に似ているから，分別沈澱がてきる筈である。 既に Sarphati $\left.{ }^{3}\right)$ 及び Mohrt) は，塩化第一銅溶液を沃化物溶液に加之ると沃化第一銅を沈澱するととを報告し ている. 更に塩化第一銅は過剩の塩素イオンの存在に执いて錯イオンの生成に上り，著しくその溶解度を增す。 Broensted 5 に上れば, $22^{\circ}$ に扬いて $\mathrm{KCl}-\mathrm{CuCl}$ 混合溶液の $100 \mathrm{~g}$ 中に $\mathrm{KCl} 3.89 \mathrm{~g}$ の時は $\mathrm{CuCl}$ の溶解度は

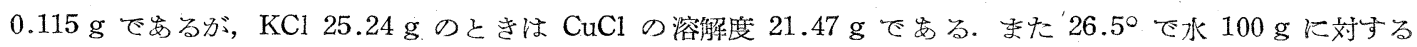
$\mathrm{CuCl}$ の溶解度 $1.55 \mathrm{~g}$ で岁る゙， $\mathrm{NaCl} 44.14 \mathrm{~g}$ が溶存すると $\mathrm{CuCl}$ の溶解度は $57.21 \mathrm{~g}$ に達する. 沃化第一 銅子過剩の沃素イオンの存在では錯イオン生成により溶解度を増すが，沃化第一銅の溶解積が小なるため，過鄱

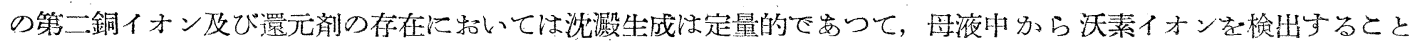
はできない。

以上の如く第一銅壏に上る沃素イオンと塩素イオンの分離は理論上可能でると考えられるが，沃化第一銅の 析出した母夜中に塩素イオンが果して定量的に残るか否かを实験に上つて検討した（な扔沃化第一銅沈潵に関す る定量的考察については別に報告する)，沈澱試薬は，硫酸酸性の硫酸銅一亜硫酸ソーダ混合溶液で岀る. Rosen一 heim, Steinhäuser( ${ }^{(3)}$ と上れば, 第二銅塩と亜硫酸アルカリとの溶液中に括いて, 銅は亜硫酸第一銅錯イオン $[\mathrm{Cu}$ $\mathrm{SO}_{3}$ Jーとして存在する.錯解離に上る第一銅イオン濃度が小であると考之られるととと, 過剩の塩素イオンの存 在に上る溶解度の堌大とに上つて塩化第一銅は沈澱するととなく，沃化第一銅の夕が沈澱する。

実験の結果によれば沃素イオン $0.5 \mathrm{~g}$ を含气溶液 $100 \mathrm{cc}$ 中に塩素イオン $0.25 \mathrm{~g}$ 以上存在する場合は，沃化 第一銅の沈澱分離後に壏素イオンは定量的に母夜中に残る. 同じ濃度の沃素イオン溶液 $100 \mathrm{cc}$ 中に塩素イオン含 量 $0.125 \mathrm{~g}$ の場合は, 滴定操作上の誤差圭考慮に入れて母夜中の塩素イオンは洊潵生成前に比べて約 $4 \%$ 減少, 塩素イオン含量 $0.0625 \mathrm{~g}$ の検液から出発した場合は約 $8 \%$ の減少が岕る. 沃素イオンに対して塩素イオンが著 しく少量なる場合に母液中に残る塩素イオンの量が沈澱生成前に比して隇少するのは, 塩素イオン濃度が小さい ために壏化第一銅の溶解度が小なる結果として，沃化第一銅に上つて共波される割合が大きくなるととによるも のと考えられる. 徒つてとの分離法は塩化物の共存量が大なる場合の分離法としては充分なるるのといらととが できる.

沃化第一銅の沈澱を分離筑の母液中の過剩の亜硫酸を除去するため過酸化水素水を加之，次にアルカリ性とな して加熱するととにより過剩の過酸化水素を分解後, 水酸化銅を除去して残存する塩素イオンを定量した。普通

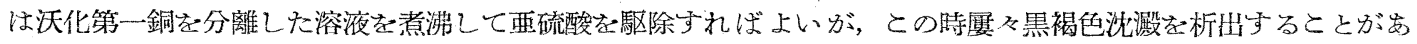

* Ueno-sakuragi-cho, Taito-ku, Tokyo.

1), 2) Bodländer, Storbeck : Z. anorg. Chem. 31, 526,465 (1902).

3) Sarphati : Z. anal. Chem. 12, 366 (1873). 4) F. Mohr : Ibid. 12, 366 (1873).

5) J. N. Brönsted : Z. physik. Chem. 80, 208, 214 (1912).

6) Rosenheim, Steinhäuser : Z. anorg. Chem. 25, 72 (1900). 
つてとれを除去する必要が起る。との沈澱物質は Rammelsberg7) によつて $\mathrm{CuSO}_{3} \cdot \mathrm{Cu}_{2} \mathrm{SO}_{3} \cdot 2 \mathrm{H}_{2} \mathrm{O}$ なる組成が

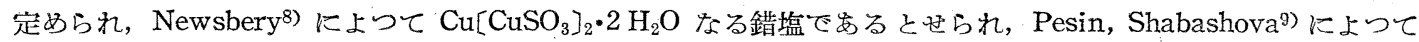
その生成機構が研究されつつ安る亚硫酸第一銅第二銅と大体に招いて組成が一致する物質で女るととを認めた。

本研究を指尊过られた京都大学高木誠司教授に謝意を表する己共に激励を与えられた村山義温学長並びに寺阪 正信部長に感謝する。

\section{実”験の 部}

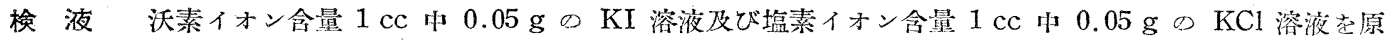
液とする。材料とする $\mathrm{KI}$ 及び $\mathrm{KCl}$ は何れも再結晶により精製した。

試 薬 $25 \% \mathrm{CuSO}_{4}, 25 \% \mathrm{Na}_{2} \mathrm{SO}_{3}, 20 \% \mathrm{H}_{2} \mathrm{SO}_{4}$ 何化名特級品を材料とし程化物不含. $25 \% \mathrm{CuSO}_{4} 25 \mathrm{cc}$, $20 \% \mathrm{H}_{2} \mathrm{SO}_{4} 20 \mathrm{cc}, 25 \% \mathrm{Na}_{2} \mathrm{SO}_{3} 25 \mathrm{cc}$ の䐓に加元る. 反応溶液の塩素イオン含量 $100 \mathrm{cc}$ 中 $0.125 \mathrm{~g}$ 以下の場

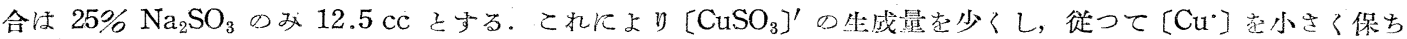

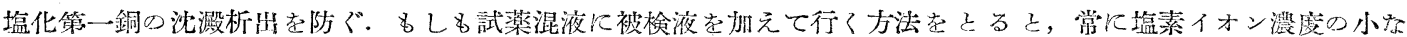
る条件で反応するために㦈化第一銅沈澱が析出し，一旦析出した沈洪は溶解困難であるから检液に試菜溶液を上

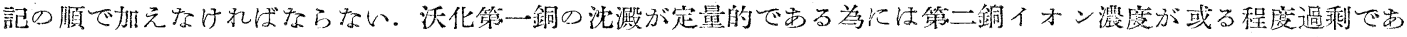

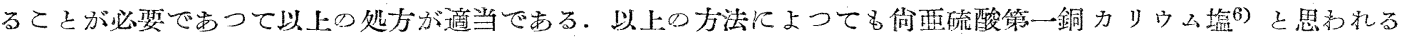

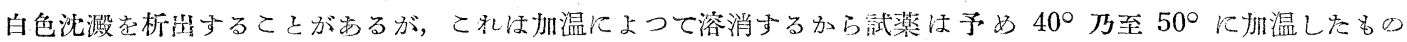
を加光る。

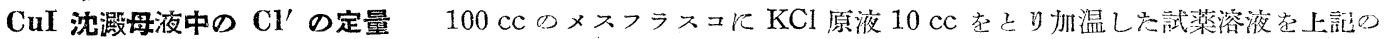
順に加えて混和し，沈澱の析出しないことを確かめた後 $\mathrm{KI}$ 原液 $10 \mathrm{cc}$ 省加え，一亘夜放置後水を加えて $100 \mathrm{cc}$ となし乾燥沪紙 (定量沪紙 $5 \mathrm{C}$ ) で沪過, 沪液 $25 \mathrm{cc}$ 取 $り$ 過酸化水素水 $1 \mathrm{cc}$ を加えて惹沸, 煮沸時塩化物不含

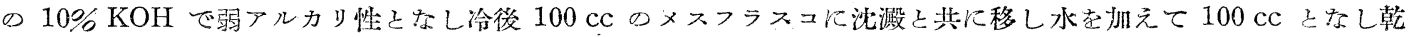
燥沪紙で沪過，沪液 $50 \mathrm{cc}$ を取りVolhard 法により塩素イオンを滴定し，これに基く塩素量と対応する計算量

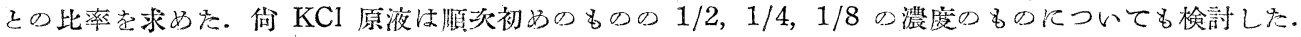

Table I

反応溶液の濃度： $\mathrm{Cl}^{\prime} 0.5 \mathrm{~g}, \mathrm{I}^{\prime} 0.5 \mathrm{~g} / 100 \mathrm{cc}$

原液の滣度： $\mathrm{KCl} 10.7117 \mathrm{~g} / 100 \mathrm{cc}$

: KI $6.5748 \mathrm{~g} / 100 \mathrm{cc}$

盲検用原液濃度： $\mathrm{KCl} 10.5972 \mathrm{~g} / 100 \mathrm{cc}$

\begin{tabular}{|c|c|c|c|c|c|c|}
\hline \multirow{2}{*}{ 実験番号 } & \multicolumn{2}{|c|}{$\mathrm{AgNO}_{3}$ 溶液 } & \multicolumn{2}{|c|}{$\mathrm{KCNS}$ 溶液 } & \multirow{2}{*}{$\begin{array}{c}\text { 滴完時の温度 } \\
\left({ }^{\circ} \mathrm{C}\right)\end{array}$} & \multirow{2}{*}{$\begin{array}{c}\text { 目液中の } \mathrm{Cl}^{\prime} \text { 比率 } \\
(\%)\end{array}$} \\
\hline & 濃 度 $(N)$ & 添加量 (cc) & 漂 度 $(N)$ & 消費量 (cc) & & \\
\hline 1 & 0.10125 & 25.00 & 0.09749 & 3.90 & 15 & 98.56 \\
\hline 2 & /I & "I & II & 3.80 & 17 & 99.62 \\
\hline 3 & " & "I & " & 3.88 & " & 98.75 \\
\hline 平均 & & & & & & 98.98 \\
\hline 盲 検 & 0.10030 & 25.00 & 0.09756 & 3.85 & 15 & 98.85 \\
\hline
\end{tabular}

Table II

反応溶液の溲度： $\mathrm{Cl}^{\prime} 0.25 \mathrm{~g}, \mathrm{I}^{\prime} 0.5 \mathrm{~g} / 100 \mathrm{cc}$

原液の浱、度： $\mathrm{KCl} 5.2360 \mathrm{~g} / 100 \mathrm{cc}$

: KI $6.5748 \mathrm{~g} / 100 \mathrm{cc}$

盲検用原液濃龸： $\mathrm{KCl} 5.4237 \mathrm{~g} / 100 \mathrm{cc}$

実験番号

$\begin{array}{ccc}1 & 0.10125 & 12.50 \\ 2 & \text { " } & 12.50 \\ 3 & 0.10047 & 15.10 \\ 4 & \text { " } & 13.00 \\ 5 & \text { " } & 12.50\end{array}$

7) Rammelberg, Pogg. : Ann. 1, 199 (1824).

8) Newberg: Am. Chem. J. 14, 232 (1892).

9) Ya. M. Pesin, M. L. Shabashova: Zhur. Prisklad. Khim. 23, 287 (1950) ; C. A. 45, 2806 (1951).
滴定時の温度 母液中の $\mathrm{Cl}^{\prime}$ 比率

\begin{tabular}{cc}
\hline 潧 度 $(N)$ & 消費量 $(\mathrm{cc})$ \\
0.09749 & 2.03 \\
" & 2.04 \\
0.09720 & 3.23 \\
" & 2.10 \\
" & 1.99
\end{tabular}

(\%)

99.12

98.99

101.42

102.30

99.13 


\begin{tabular}{|c|c|c|c|c|c|c|}
\hline 6 & 0.10125 & 12.50 & 0.09749 & 1.67 & $15 \sim 17$ & 106.09 \\
\hline 7 & 0.10047 & 12.50 & 0.09720 & 2.20 & II & 94.36 \\
\hline 8 & "I & 10.50 & "I & 0.90 & 15 & 100.24 \\
\hline 9 & " & 12.50 & "I & 1.83 & 13 & 99.02 \\
\hline 10 & "I & 12.50 & "I & 1.83 & 14 & 99.01 \\
\hline 平 均 & & & & & & 99.98 \\
\hline 盲 検 & 0.10020 & 12.50 & 0.09953 & 1.83 & 15 & 98.34 \\
\hline \multicolumn{7}{|c|}{ Table III } \\
\hline \multicolumn{7}{|c|}{ 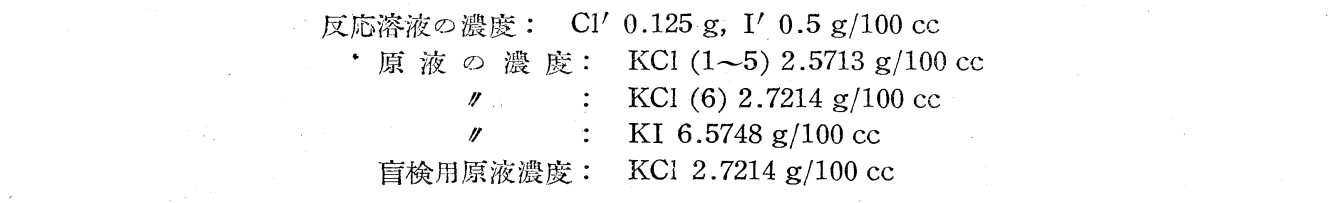 } \\
\hline 实駼番是 & \multicolumn{2}{|c|}{$\mathrm{AgNO}_{3}$ 溶液 } & \multicolumn{2}{|c|}{$\mathrm{KCNS}$ 溶液 } & \multirow{2}{*}{$\begin{array}{c}\text { 滴定時の温店 } \\
\left({ }^{\circ} \mathrm{C}\right)\end{array}$} & \multirow{2}{*}{$\begin{array}{c}\text { 母液中の } \mathrm{Cl}]^{\prime} \text { 比率 } \\
(\%)\end{array}$} \\
\hline 大陌的与 & 浱 度 $(N)$ & 添加量 (cc) & 濃 度 $(N)$ & 消費量 (cc) & & \\
\hline 1 & 0.10047 & 10.00 & 0.09720 & 2.93 & $12 \sim 14$ & 100.92 \\
\hline 2 & "I & "I & II & 3.00 & 15 & 97.47 \\
\hline 3 & "I & "I & "I & 2.98 & "I & 98.59 \\
\hline 4 & "I & "I & "I & 3.01 & $15 \sim 17$ & 97.06 \\
\hline 5 & " & 11.50 & "I & 3.80 & 11 & 96.40 \\
\hline 6 & "I & 10.00 & "I & 2.95 & 13 & 97.39 \\
\hline 平均 & & & & & & 97.97 \\
\hline \multirow[t]{3}{*}{ 目 検 } & 0.1003 & "I & 0.09756 & 2.80 & 15 & 100.09 \\
\hline & \multicolumn{6}{|c|}{ Table IV } \\
\hline & \multicolumn{6}{|c|}{ 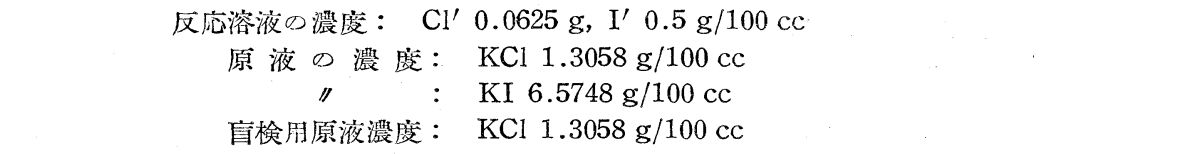 } \\
\hline
\end{tabular}

实験番号

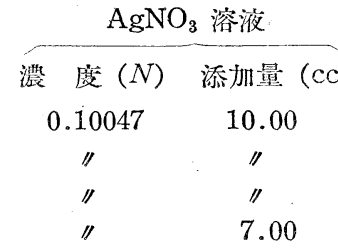

$\mathrm{KCNS}$ 溶液

\begin{tabular}{|c|c|}
\hline 溲 度 $(N)$ & 消費量 (cc) \\
\hline 0.09720 & 4.15 \\
\hline "I & 4.13 \\
\hline "I & 4.16 \\
\hline " & 2.60 \\
\hline
\end{tabular}

$0.09756 \quad 4.10$
滴定時の温度 母液中の $\mathrm{Cl}^{\prime}$ 比率

$\left({ }^{\circ} \mathrm{C}\right) \quad(\%)$

90.43

92.20

89.53

90.64

90.64

93.58

15

盲 検

$0.10030 \quad 10.00$

誤差を考虑す る必要がある. 故に比較のためI から IV むでの滴定時こ大体等しい濃度の KCl 溶液を直接滴定して Table V の結果を得た.

Table V

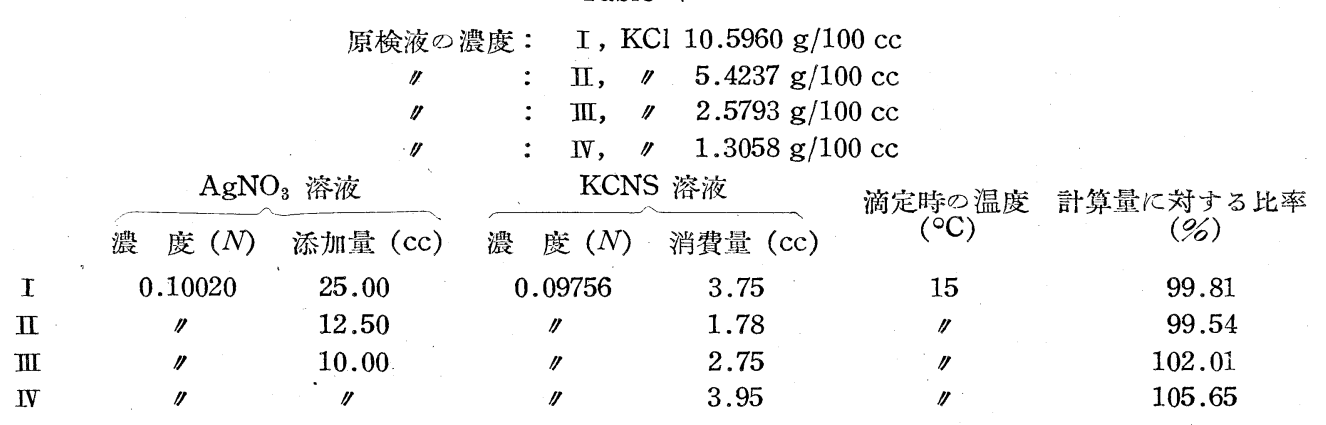




\section{Summary}

Treatment of silver salts with ammonia is the usual method in isolating the iodine and chlorine ions but such a method necessitates decomposition of each silver salt separately after treatment with ammonia, which is somewhat tedious in analytical procedures. A method of isolation using the difference in the solubility of the cuprous salt of each ion was examined and it was thereby found that a sufficiently satisfactory results are obtained except when the concentration of the chloride is extremely small. If this isolation method can be carried out quantitatively, qualitative estimation of each ion, in the presence of both halogen ions, can be made more simply than by the silver salt method. Moreover, such method of isolation can possibly be utilized for the quantiative determination of each ion in the presence of the two halogen ions or of each element in organic compounds possessing both iodine and chlorine in their molecule.

(Received June 1, 1954)

267. 万木庄次郎, 烃岡敏郎, 富樫 誠：Allium 属植物成分と Vitamin $\mathrm{B}_{1}$ との反応 に関する研究 $(6)$ (Vitamin $B_{1}$ 及び諸関係化合物の研究 第 61 報*)

Shojiro Yurugi, Toshiro Matsuoka, and Makoto Togashi : Studies on Vitamin $\mathrm{B}_{1}$ and Related Compounds. LXI. Studies on the Reaction between Thiamine and Ingredients of the Plants of Allium Genus. (6).

(Research Laboratory, Takeda Pharmacentical Industries, Ltd.**)

allithiamine 括よびその同族体は L-cysteine で容易に thiamine (以後 $\mathrm{B}_{1}$ 之略称) に還元され，同時に Salkylmercapto-L-cysteine が生成与る1,2)。ととに生成する S-alkylmercapto-L-cysteine (IX, X, XI) を, paper partition chromatography (PPC) にかけると, alkyl 基の相異に上りそれぞれ買る分別像を形成し，各自が上 く分離検出される，従つてもとの allithiamine 同族体の種頑が容易に判別できる2).との方法を用いてAllium 属植物成分と $\mathrm{B}_{1}$ との反応成績体を検索した結果, allithiamine (VI), その methyl 同族体て岕る thiamine methyl disulfide (TMD; VII) 特よび thiamine propyl disulfide (TPD； VIII)の生成をかなり広範囲に認めた.

との際ラッキョウ（A. Bakeri Regel）に执いては，その採集時期に上り $\mathrm{B}_{1}$ との反応成績体が著しく相異する 事実を認めたので3)，とれ等の植物の含有成分は季節的にかなり変動するのではないかと考竞られる. そとで今

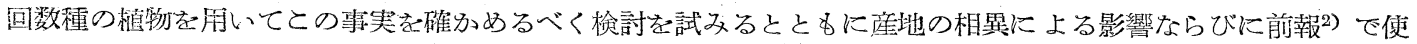
用した植物以外のAllium 属植物呿上び近縁䐜物と $\mathrm{B}_{1}$ との反応成績体につき, PPC を用いて榆掌した.

季節的変化に関しては植物として比較的入手し易いギョウジャニンニク (A. victorialis L. var. platyphyllum

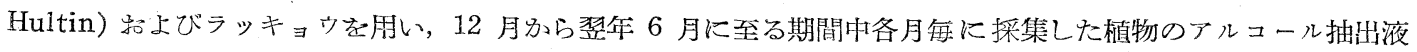
と $\mathrm{B}_{1}$ とを常法通り反応させ，反応の進行状沉ならびにその成績体を検べた．その結果ギョウジャニンニクでは 殆んど時期に上る変動を認めなかつたが，ラッキョウでは明らかに反応成績体に変化が認められ，2４月に採取 した植物ては allithiamine 化合物の生成は著しく悪く，さきに認められた事実 ${ }^{3)}$ は予想通り成分の季節的变動

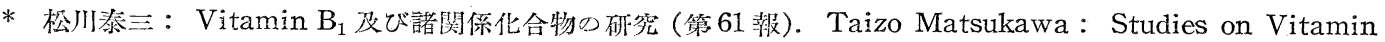
$\mathrm{B}_{1}$ and Related Compounds. LXI.

** Juso-nishino-cho; Higashiyodogawa-ku, Osaka.

1) 松川，万木，松汕： Science 118，325 (1953)；万木：本誌 74, 511 (1954).

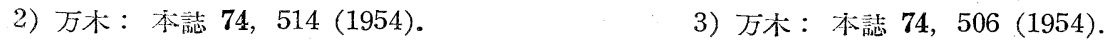

